\title{
Vocal cord paralysis in the Shy-Drager syndrome
}

\author{
A D R I N W I L L A MS, DAVID HA NSON, A N D \\ D O N A L D B. CAL NE
}

\begin{abstract}
From the Experimental Therapeutics Branch and Communicative Disorders Program, National Institute of Neurological and Communicative Disorders and Stroke, National Institutes of Health, Bethesda, Maryland, USA
\end{abstract}

SUMMARY Eight out of 12 unselected patients with Shy-Drager syndrome were found to have severe bilateral paresis of vocal cord abduction by fibre-optic laryngoscopy. This commonly presented as increased snoring followed by episodes of inspiratory and expiratory stridor and sometimes by sleep apnoea. Respiratory failure eventually developed in four cases and was reversed by tracheostomy. In another patient tracheostomy relieved severe attacks of sleep apnoea. This complication was not necessarily associated with advanced disease, and it should be considered in all patients with Shy-Drager syndrome as appropriate treatment can lead to a useful extension of life.

Bilateral vocal cord paralysis is uncommon but important to recognise since it can lead to respiratory failure. Our experience of this complication in a patient with Shy-Drager syndrome prompted us to investigate vocal cord function in a series of patients with this condition as it provides a treatable component of this disease.

\section{Methods}

Twelve consecutive patients with the classical features of Shy-Drager syndrome were investigated. Their chief clinical features and severity are summarised in Table 1 , using a scale of 0 (normal) to 4 (severe).

All patients were questioned specifically about any respiratory difficulties, particularly changes in degree of snoring and episodes of stridor or apnoea at night. Evidence was also sought from the patients' spouses.

Vocal cords were examined with a fibre-optic laryngoscope by the same observer and their movement noted at rest, during inspiration, expiration, and phonation. The maximal abduction was graded on the following scale: $0=$ no abnormality; $1=$ equivocal paresis; $2=$ mild paresis; $3=$ marked paresis but more than $2 \mathrm{~mm}$ separation during inspiration; $4=$ complete paralysis with cords in close apposition during maximum inspiration.

Address for reprint requests: Dr Adrian Williams, National Institutes of Health, Building 10, Room 3D12, Bethesda, Maryland 20014, USA. Accepted 18 August 1978

\section{Results}

Respiratory symptoms, the vocal cord findings, and their treatment are summarised in Tables 2 and 3.

Moderate or severe bilateral paralysis of vocal cord abduction was present in eight out of 12 of our patients. Airway symptoms usually started with an increase in snoring, and later inspiratory and expiratory stridor developed, which was initially intermittent and at night. The degree of vocal cord paralysis could fluctuate considerably, and it was possible for severe airway obstruction to develope acutely. Episodes of sleep apnoea were present in two patients and occurred after a crescendo of increasing snoring and progressive stridor. Four patients required tracheostomy for frank respiratory failure and one for severe attacks of sleep apnoea.

One patient (case 3) developed severe respiratory complications at an early stage of the disease when there were no other definite symptoms of Parkinsonism, and another patient (case 7) had significant, but asymptomatic, vocal cord paralysis despite only mild Parkinsonism.

One patient (case 11) who had a unilateral paresis initially, developed, one year later, nocturnal stridor and apnoeic attacks associated with severe bilateral vocal cord paralysis. His extrapyramidal and autonomic syndrome was by then severe, and the patient and his relatives declined a tracheostomy. He subsequently died from a respiratory arrest in his sleep. 
Table 1 Clinical features of Shy-Drager patients

\begin{tabular}{|c|c|c|c|c|c|c|c|c|}
\hline Patient & $\begin{array}{l}\text { Age } \\
(y r)\end{array}$ & Sex & $\begin{array}{l}\text { Disease } \\
\text { duration } \\
(y r)\end{array}$ & Parkinsonism & $\begin{array}{l}\text { Cerebellar } \\
\text { dysfunction }\end{array}$ & $\begin{array}{l}\text { Bulbar } \\
\text { dysfunction }\end{array}$ & $\begin{array}{l}\text { Postural } \\
\text { hypotension }\end{array}$ & $\begin{array}{l}\text { Sexual and } \\
\text { sphincter } \\
\text { dysfunction }\end{array}$ \\
\hline 1 & 57 & $\mathbf{M}$ & 4 & 3 & 2 & 3 & 3 & 2 \\
\hline 2 & 57 & $\mathbf{M}$ & 8 & 3 & 2 & 2 & 3 & 3 \\
\hline 3 & 56 & $\mathbf{M}$ & 5 & 3 & 0 & 3 & 3 & 4 \\
\hline 4 & 63 & $\mathbf{M}$ & 2 & 2 & 2 & 3 & 2 & 2 \\
\hline 5 & 64 & $\mathbf{F}$ & 5 & $\overline{3}$ & $\overline{3}$ & 3 & 4 & 3 \\
\hline 7 & 61 & $\mathbf{F}$ & 4 & 1 & 0 & 0 & 1 & 1 \\
\hline 8 & 58 & $\mathbf{M}$ & 8 & 2 & 2 & 1 & 3 & 2 \\
\hline 9 & 68 & $\mathbf{M}$ & 3 & 3 & 1 & 3 & 4 & 3 \\
\hline 10 & 55 & $\mathbf{M}$ & 8 & 3 & 2 & 1 & 2 & 4 \\
\hline 11 & 64 & $\mathbf{M}$ & 4 & 3 & 0 & 1 & 3 & 3 \\
\hline 12 & 57 & $\mathbf{M}$ & 2 & 1 & 1 & 1 & 2 & 2 \\
\hline
\end{tabular}

Table 2 Respiratory and vocal cord symptoms

\begin{tabular}{lllll}
\hline Patient & $\begin{array}{l}\text { Increased } \\
\text { snoring }\end{array}$ & Stridor & $\begin{array}{l}\text { Sleep } \\
\text { apnoea }\end{array}$ & $\begin{array}{l}\text { Hoarse } \\
\text { voice }\end{array}$ \\
\hline 1 & 2 & 3 & 3 & 0 \\
2 & 4 & 4 & 4 & 0 \\
3 & 4 & 4 & 0 & 0 \\
4 & 2 & 3 & 0 & 0 \\
5 & 2 & 2 & 0 & 0 \\
6 & 2 & 1 & 0 & 0 \\
7 & 1 & 0 & 0 & 0 \\
8 & 0 & 0 & 0 & 0 \\
9 & 0 & 0 & 0 & 3 \\
10 & 1 & 0 & 0 & 2 \\
11 & 1 & 0 & 0 & 0 \\
12 & 0 & 0 & 0 & 0 \\
\hline
\end{tabular}

Table 3 Vocal cord findings, respiratory status, and treatment

\begin{tabular}{rllll}
\hline Patient & $\begin{array}{l}\text { Bilateral } \\
\text { abductor } \\
\text { paresis }\end{array}$ & $\begin{array}{l}\text { Unilateral } \\
\text { paresis }\end{array}$ & $\begin{array}{l}\text { Chronic } \\
\text { respiratory } \\
\text { failure }\end{array}$ & Tracheotomy \\
\hline 1 & 4 & 0 & Present & Performed \\
2 & 4 & 0 & - & Performed \\
3 & 4 & 0 & Present & Performed \\
4 & 4 & 0 & Present & Performed \\
5 & 4 & 0 & Present & Performed \\
6 & 3 & 0 & - & - \\
7 & 3 & 0 & - & - \\
8 & 2 & 0 & - & - \\
9 & 3 & 0 & - & - \\
10 & 0 & 3 & - & - \\
11 & 0 & 3 & - & - \\
12 & 0 & 0 & & - \\
\hline
\end{tabular}

Dysarthria was common but hoarseness of the voice was unusual. The degree of speech disturbance was of no value in predicting the severity of the vocal cord paresis.

All patients treated with a tracheostomy derived relief from their respiratory symptoms. A permanent skin-flap lined tracheal stoma was used and the tracheostomy plugged during the day, or a Tucker valve employed, to allow the patient to speak. This was felt to be preferable to surgical abduction of a vocal cord which, although avoiding tracheostomy, would interfere severely with speech.

\section{Discussion}

The Shy-Drager syndrome usually manifests itself in middle age as a progressive pan-autonomic failure with the later development of atypical Parkinsonism and a cerebellar deficit (Shy and Drager, 1960; Thomas and Schirger, 1970). There have been two previously reported cases of this disease who developed stridor and respiratory failure requiring tracheostomy (Roessmann et al., 1971; Israel and Marino, 1977). Two patients have also been described with typical Parkinson's disease who had glottic obstruction because of vocal cord paralysis (Vas et al., 1965). Thus severe vocal cord paresis is not specific to the extrapyramidal defect in the Shy-Drager syndrome although it seems to be much more common and severe. We feel that the development of a severe vocal cord dysfunction in a patient with a progressive Parkinsonism, cerebellar, or autonomic deficit is suggestive of the diagnosis of the ShyDrager syndrome.

Severe degeneration in the pigmented dorsal nucleus, the vagal parasympathetic centre, has been described frequently in patients with the ShyDrager syndrome (Roessmann, 1975) but there is little information on the pathology of the vagal nuclei supplying motor control to the laryngeal muscles. The fibres of the vagus nerve which supply the laryngeal muscles of abduction arise in the nucleus ambiguus and in the retrofacial nucleus (Haymaker, 1969). Degeneration in these nuclei is likely to be responsible for the vocal cord paresis as well as for the loss of palatal control, presumably the cause of the snoring, that characterises the respiratory difficulties of these 
patients. Clinicopathological correlations would be of interest to define further the brainstem pathology.

It is surprising that such an apparently common complication has been generally overlooked. However, in one series two out of four patients had severe laryngeal obstruction thought at the time to be caused by disturbance of the pneumotaxic centre despite the presence of stridor (Bannister and Oppenheimer, 1972). It is probable that many patients with the Shy-Drager syndrome develop this problem and may die as a consequence of it. One reason for an oversight of the laryngeal obstruction is that stridor may not be obvious because of weakness of inspiratory muscles, which is commonly present in advanced cases. This weakness also decreases the inspiratory pull of the larynx downwards, which contributes to opening of the glottis (Fink, 1975) and exacerbates the paresis of abduction. A similar combination of vocal cord paresis and weakness of inspiratory muscles can arise in myasthenia gravis or in some polyneuropathies, where serious laryngeal obstruction is probably more common than is usually recognised.

Sleep apnoea is now well recognised as a presentation of upper airway obstruction (Guilleminault et al., 1973) and may be fatal. One patient with the Shy-Drager syndrome who died during an episode of sleep apnoea is reported to have had only a unilateral vocal cord paresis (Guilleminault et al., 1977); his episodes of apnoea were thought to be caused, in some unexplained way, by the autonomic defect. It appears to us that apnoeic spells are more likely to be the results of episodes of complete laryngeal obstruction. Thus severe snoring, with or without stridor and apnoeic attacks, requires urgent consideration for a careful examination of the vocal tract and possible elective tracheostomy to avoid the added insult of anoxia to an already compromised central nervous system.

Patients with the Shy-Drager syndrome should be examined routinely for laryngeal dysfunction and the examination repeated if suggestive symptoms develop. Fibre-optic laryngoscopy should be used, if possible, as paresis of vocal cord abduction is easier to assess with this procedure than by conventional techniques.

We would like to thank our patients, their referring physicians, and the nurses of 5 West. We are grateful to Ms P. Barnicoat and Ms B. Shryock for typing the manuscript.

\section{References}

Bannister, R., and Oppenheimer, D. R. (1972). Degenerative diseases of the nervous system associated with autonomic failure. Brain, 95, 457-474.

Fink, B. R. (1975). The Human Larynx, vol. 12, pp. 67-74. Raven Press: New York.

Guilleminault, C., Eldreidge, F. L., and Dement, W. C. (1973). Insomnia with sleep apnea: a new syndrome. Science, 181, 856-858.

Guilleminault, C., Tilkian, A., Lehrman, K., Forno, L., and Dement, W. C. (1977). Sleep apnoea syndrome: states of sleep and autonomic dysfunction. Journal of Neurology, Neurosurgery, and Psychiatry, 40, 718-725.

Haymaker, W. (1969). Localisation of lesions involving cranial nerves IX through XII. In Bing's Local Diagnosis in Neurological Diseases. Fifteenth edition, pp. 170-185. C. V. Mosby: St Louis.

Israel, R. H., and Marino, J. M. (1977). Upper airway obstruction in the Shy-Drager syndrome. Annals of Neurology, 2, 83.

Roessmann, U. (1975). Primary orthostatic hypotension. In Handbook of Clinical Neurology, vol. 22, pp. 231-242. Edited by P. J. Vinken and G. W. Bruyn. North Holland: Amsterdam.

Roessmann, U., Van Den Noort, S., and McFarland, D. E. (1971). Idiopathic orthostatic hypotension. Archives of Neurology (Chicago), 24, 503-510.

Shy, G. M., and Drager, G. A.fl (1960). A neurological syndrome associated with orthostatic hypotension. Archives of Neurology (Chicago), 2, 511-527.

Thomas, J. E., and Schirger, A. (1970). Idiopathic orthostatic hypotension. A study of its natural history in 57 neurologically affected patients. Archives of Neurology (Chicago), 22, 289-293.

Vas, C. J., Parsonage, M., and Lord, O. C. (1965). Parkinsonism associated with laryngeal spasm. Journal of Neurology, Neurosurgery, and Psychiatry, 28, 401-403. 